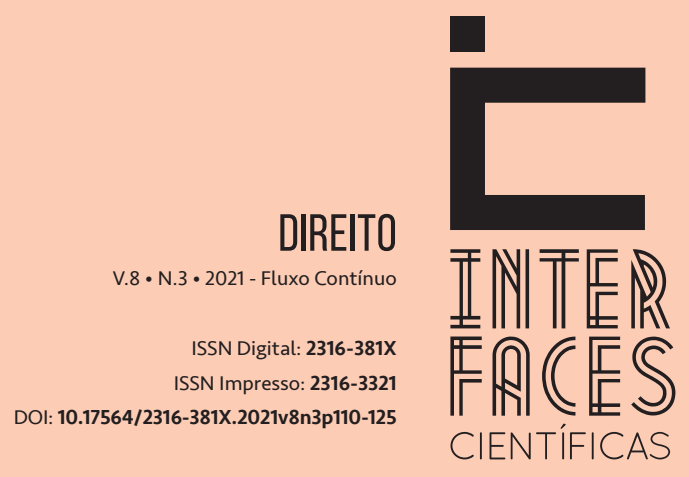

\section{AUTOPLÁGIO NA PESQUISA CIÊNTÍFICA: UM ILÍCITO?}

SELFPLAGE IN SCIENTIFIC RESEARCH: AN ILLICIT?

AUTOPLAGIO EN INVESTIGACIÓN CIENTÍFICA: ZLLIICITA?

Samyr Leal da Costa Brito ${ }^{1}$

\section{RESUMO}

O autoplágio é desmotivado pela academia, mas existe a dúvida se se trata de um ilícito ou é apenas uma infração ética. Esse trabalho busca responder à essa dúvida, para tanto utilizou-se de uma pesquisa exploratória, utilizando dos métodos bibliográfico e documental. Analisou-se a relação do autoplágio com o direito autoral, com a boa-fé, com as relações obrigacionais e com o costume jurídico. Chegou-se à conclusão de que a repressão ao autoplágio é um costume jurídico dentro das instituições acadêmicas atentatório à boa-fé e pode configurar-se uma violação da relação obrigacional. Dessa forma, dentro desses contextos o autoplágio pode ser considerado como um ilícito, mas em outras situações, poderá ser apenas uma infração ética.

\section{PALAVRAS-CHAVES}

Plágio. Integridade científica. Direito autoral. 


\section{ABSTRACT}

Self-plagiarism is discouraged by academia, but there is a doubt if it is an offense or is it just an ethical infraction. This work seeks to answer this question, for which exploratory research was used, using bibliographic and documentary methods. The relationship between self-plagiarism and copyright, good faith, obligatory relationships and legal custom was analyzed. It was concluded that the repression of self-plagiarism is a legal custom within academic institutions, as well as a violation of good faith and may constitute a violation of the obligatory relationship. Thus, within these contexts, self-plagiarism can be considered an illicit act, but in other situations, it may only be an ethical violation.

\section{KEYWORDS}

Plagiarism. Scientific integrity. Copyright.

\section{RESUMEN}

El mundo académico desaconseja el autoplagio, pero existe la duda de si es una ofensa o es solo una infracción ética. Este trabajo busca dar respuesta a esta pregunta, para lo cual se utilizó una investigación exploratoria, utilizando métodos bibliográficos y documentales. Se analizó la relación entre el autoplagio y los derechos de autor, la buena fe, las relaciones obligatorias y la costumbre legal. Se concluyó que la represión del autoplagio es una costumbre legal dentro de las instituciones académicas, así como una violación de la buena fe y puede constituir una violación de la relación obligatoria. Por lo tanto, dentro de estos contextos, el autoplagio puede considerarse un acto ilícito, pero en otras situaciones, puede ser solo una violación ética.

\section{PALABRAS CLAVE}

Plagio. Integridad científica. Derecho autoral. 


\section{INTRODUÇ̧̃̃o}

O comportamento ético sempre foi uma preocupação acadêmica, tendo em vista que desvios morais na pesquisa podem induzir a resultados que não sejam assertivos e prejudiquem, direta ou indiretamente, o avanço científico.

Em razão disso, muito se discute sobre a integralidade e boas práticas na pesquisa científica, o que envolve temas como compromisso do indivíduo, a honestidade intelectual, conflito de interesses entre pesquisadores e financiador de estudos, falsificação de dados, plágio, entre outros (DAMASIO, 2017).

Atualmente, no âmbito acadêmico, o pesquisador e os programas de pesquisas têm sido avaliados muito mais pela quantidade de publicações do que pelo impacto das pesquisas que realizam. 0 número de publicações pode ser decisivo, inclusive, em uma competição para obtenção de recursos financeiros para uma pesquisa. Essa cultura produtivista impregnada na academia brasileira tem colaborado para o surgimento do autoplágio, isto é, do autor utilizar uma obra sua, total ou parcialmente, anteriormente publicada, como se fosse inédita, para com isso aumentar o seu número de publicações (MAIA, 2017, p. 1; CARVALHO; BRITO, 2018, p. 39; ASSIS; HOLANDA; AMORIM, 2019, p. 96).

A maioria dos pesquisadores identificam essa prática como danosa para o conhecimento científico (DAMASIO, 2017, p. 120), embora existam aqueles, uma minoria, que entendem que o autoplágio é necessário para a construção do conhecimento (DINIZ; TERRA, 2014, p. 58), ou que não possui tanta relevância, sendo apenas um modismo de época ou histeria acadêmica (SATUR; DIAS; SILVA, 2020, p. 73).

O fato é que instituições de ensino e pesquisa, editores, revistas científicas, entre outros, têm adotado a prática de reprovar ou solicitar alteração de trabalhos contendo autoplágio. Alguns desses têm incluído a repressão ao autoplágio em suas políticas editoriais, guia de boas práticas de pesquisa e em regimento interno.

Diante disso, este trabalho procura responder à seguinte problemática: o autoplágio na pesquisa científica é um ilícito? Aqui se entende o ilícito como ato humano contrário ao direito, e, portanto, passível de sanção jurídica.

Logo, o objetivo geral da pesquisa é responder a esse problema. Como seu desdobramento, estabeleceram-se os seguintes objetivos específicos: a) compreender o autoplágio; b) verificar se o autoplágio pode ser justificado pelo direito do autor; c) analisar se o autoplágio constitui uma transgressão à boa-fé; d) estudar o impacto do autoplágio nas relações obrigacionais; d) verificar se a repressão ao autoplágio pode constituir-se em um costume jurídico. Para cada um desses objetivos, foi dedicado um tópico, que seguem à mesma ordem de apresentação dos respectivos itens.

Para responder à problemática, optou-se por uma pesquisa de caráter exploratório e utilizou-se dos métodos bibliográficos e documental, por meio dos quais, buscou-se reunir o material acadêmico e institucional, direta e indiretamente relacionado à pesquisa, constituído de livros, artigos, dissertações, normas, decisão judicial e guias de boas práticas em pesquisa científica. Todo o material foi utilizado para se compreender melhor o tema e construir um arcabouço teórico que fosse suficiente para responder o problema da pesquisa.

A reunião do material bibliográfico decorreu de busca nas bases científicas: Google Acadêmico e Biblioteca Digital Brasileira de Teses e Dissertações (BDBTS). Para a localização dos guias de boas 
práticas em pesquisa científica, utilizou-se o buscador na internet do Google. Já para a busca de jurisprudência, fez uso do sistema JusBrasil. A pesquisa ocorreu no mês de dezembro de 2020.

\section{AUTOPLÁGIO E SUAS CONSEQUÊNCIAS}

O termo autoplágio trata-se da junção de duas palavras: o prefixo grego “auto", que se refere a "si mesmo" e o termo jurídico "plágio", o qual trata-se da usurpação intelectual, isto é, apresentar o trabalho de uma outra pessoa, total ou parcialmente, como se fosse próprio (AFONSO, 2009, p. 121; COSTA, 2019).

Nesse contexto, interpretando literalmente o termo "autoplagio", este assumira o significado de furtar a si mesmo, e, como afirma Diniz e Terra (2014, p. 58), implicaria "em um oximoro, isto é, em uma contradição", tendo em vista que para que exista o furto é necessário que existam duas pessoas, o furtador e a vítima, e, no caso do autoplágio, existe apenas uma única pessoa (SATUR; DIAS; SILVA, 2020, p. 70).

Por mais que o termo seja inadequado, é preciso ter em mente que as palavras, em regra geral, são utilizadas de forma desassociada de seu objeto e se recepcionada socialmente, passa a ter validade (SAUSSURE, 2006, p. 81-82). É nessa esteira que o termo autoplágio é de uso corrente no âmbito acadêmico, sendo usado por pesquisadores e por documentos institucionais.

A Tabela 1 apresenta algumas definições para autoplágio no âmbito acadêmico nacional:

Tabela 1 - Definições de autoplágio

AUTOR DEFINIÇÃO

Relatório da Comissão de Integridade de Pesquisa do Conselho Nacional de Desenvolvimento Científico e Tecnológico - CNPq (2011)

\section{Academia Brasileira de Ciências (2013)}

DAMASIO (2017, p. 68).

CAMARGOS (2018, p. 28).
Autoplágio: consiste na apresentação total ou parcial de textos já publicados pelo mesmo autor, sem as devidas referências aos trabalhos anteriores.

Republicação de resultados científicos já divulgados, como se fossem novos, sem informar publicação prévia.

O autoplágio é definido como plagiar a si mesmo, é a reutilização ou duplicação, parcial ou na integral, de conteúdo próprio, já publicado e disseminado anteriormente.

O autoplágio consiste na utilização de obra ou de trecho de obra própria como se fosse original []. A questão aqui afigura-se mais como conduta inapropriada, antiética e, portanto, indesejável. 
CARVALHO; BRITO (2018, p. 48).

\section{Guia para integridade da pesquisa científica da Universidade Federal do Rio Grande do Sul (2020)}

Consiste na utilização de forma total ou parcial de manuscritos já publicados pelo mesmo pesquisador como se inédito fosse.

Republicação de dados próprios na íntegra ou partes substanciais de trabalhos publicados anteriormente, incluindo tradução, sem a devida citação à fonte original

Fonte: 0 autor (2021).

Os conceitos da Tabela 1 têm como ponto em comum definir o autoplágio como o fato de autores utilizarem um material seu, já publicado, de forma total ou parcial, como se fosse inédito. Entretanto, divergem pontualmente sobre a extensão do autoplágio. Essa divergência se dá porque há tipos de autoplágio e os referidos conceitos fixam em uma ou mais de suas modalidades, que são as seguintes:

a) Publicação duplicada: é a prática de submeter um mesmo trabalho para mais de um periódico, sem sinalizar à existência da versão originalmente publicada. Isso pode se dar tanto de forma integral (os trabalhos serem idênticos entre si), como de forma levemente parcial, (quando a mudança ocorre apenas no título e/ou na forma de expor o conteúdo). Uma outra forma dessa modalidade de autoplágio é quando o autor utiliza integralmente da pesquisa realizada em um curso concluído, em um curso que está cursando, como critério de aprovação (ROIG, 2015, p. 17; BARRAGÁN-VERGEL, 2018, p. 293; ASSIS; HOLANDA; AMORIM, 2019, p. 96).

b) Publicação redundante: é a prática de apresentar dados como se fossem novos, quando na verdade constam em pesquisa anterior. Essa prática pode se dar de diversas formas: quando o autor acrescenta dados novos aos antigos e faz o leitor acreditar que todos os dados são novos; quando o autor retira dados da pesquisa original e os publica como se fosse uma nova pesquisa; quando o autor reanalisa os dados por meio de uma nova técnica, mas sem sinalizar que os dados se referem a uma pesquisa anterior (CULEBRAS; GARCÍA DE LORENZO; SANZ-VALERO, 2009, p. 376; ROIG, 2015, p. 18).

c) Reciclagem de texto: trata-se da reutilização de parágrafos, tópicos ou capítulos de um trabalho já publicado em um novo trabalho, sem referendá-lo. Entretanto, existe a discussão até que ponto a autocitação sem referenciamento pode constituir-se como autoplágio, como por exemplo, se à reciclagem tratar-se de uma paráfrase apropriada ou se o texto for atualizado conforme a norma padrão ou técnica (ROIG, 2015, p. 21; CARVALHO; BRITO, 2018, p. 41; ASSIS; HOLANDA; AMORIM, 2019, p. 96)

Todas essas práticas são danosas ao conhecimento científico. Numa perspectiva geral, porque enganam os leitores e editores, fazendo-os acreditar que se trata de materiais inéditos; violam os direitos dos editores, na medida que descumprem a cessão direitos autorais que é feita a estes por parte dos autores; proporciona um aumento de publicações que não reverberam, necessariamente, em impacto social ou científico; e dificulta a identificação de textos, por partes de pesquisadores, que agreguem dados relevantes em suas pesquisas (MAIA, 2017, p. 1; BARRAGÁN-VERGEL, 2018, p. 293; FURLANETTO; RAUEN; SIEBERT, 2018, p. 14; REJOWSKI; RODRIGUES, 2018, p. 821-822; ASSIS; HOLANDA; AMORIM, 2019, p. 97-98). 
Numa perspectiva mais específica há outros danos. No caso da duplicidade, rouba de outros autores a oportunidade de publicar um artigo verdadeiramente original e pode proporcionar análises estatísticas equivocadas por parte de outros pesquisadores. As práticas de publicação redundante podem conduzir pesquisadores que utilizem de revisão de literatura, a chegar a uma conclusão distorcida, frente à realidade dos dados, tendo em vista eles serem apresentados de forma aumentada, fragmentada ou sobreposta. Por fim, a reciclagem de texto é uma forma de violação aos princípios éticos da integralidade científica e da escrita, podendo, inclusive, configurar-se como uma violação ao direito do editor (ROIG, 2015, p. 16-26; ASSIS; REJOWSKI; RODRIGUES, 2018, p. 821-822; HOLANDA; AMORIM, 2019, p. 98).

Embora o autoplágio gere todas essas situações negativas para a produção do conhecimento e exista um grande apelo por parte da academia para desmotivá-lo, inclusive por meio de sanções institucionais, ainda não é considerado de relevância suficiente para ser positivado como crime ou como ilícito civil, tal como ocorre com as violações do direito do autor (CARVALHO; BRITO, 2018, p. 47; FURLANETTO; RAUEN; SIEBERT, 2018, p. 14; REJOWSKI; RODRIGUES, 2018, p. 814).

\section{AUTOPLÁGIO E DIREITOS MORAIS DO AUTOR}

A doutrina vem compreendendo que o direito do autor tem dois aspectos: um patrimonial e outro moral (AFONSO, 2009). Inclusive, isso é previsto na Lei n 9.610, de 19 de fevereiro de 1998 (Lei de Direitos Autorais - LDA), no art. 22 que diz: "pertencem ao autor os direitos morais e patrimoniais sobre a obra que criou" (BRASIL, 1998).

0 direito patrimonial refere-se à exploração econômica que o autor pode fazer de sua obra. Por meio dele, o autor tem direito exclusivo de utilizar, fruir e dispor de sua obra, bem como, autorizar sua utilização ou fruição por terceiros (COSTA NETO, 2019, p. 258).

Já o direito moral é um desdobramento do direito da personalidade do Autor, como direito à integralidade intelectual (CARVALHO; BRITO, 2018, p. 7), relacionado com o vínculo do autor com a sua criação (PAESANI, 2015, p. 13).

A Tabela 2, elaborada a partir da LDA (1998, art. 24), Afonso (2009, p. 35-37), Souza (2013), Wachowicz (2014, p. 5-6) e Costa Neto (2019, p. 251-252), informa as prerrogativas contidas no direito moral do autor:

Tabela 2 - Direitos morais do autor

\section{DIREITOS}

Direito ao inédito

Direito à paternidade

Direito a integridade

\section{DEFINIÇÃ̃o}

Faculdade que o autor possui em não divulgar a sua obra.

Garantida de que a autoria da obra está vinculada ao nome do autor, pseudônimo ou sinal convencional indicado ou anunciado.

Possibilidade que o autor possui de opor-se a

qualquer modificação em sua obra. 
Direito de alteração

Direito de arrependimento
Prerrogativa que o autor possui de alterar a sua obra antes e depois de utilizada.

Fonte: O Autor (2020)

Questiona-se, analisando o autoplágio sob o espectro desses direitos: o autoplágio encontra legitimação no direito moral do Autor?

A partir da Tabela 2, percebe-se que nenhum dos direitos que compõe o direito moral do autor contempla a possibilidade de alguém reaproveitar um trabalho seu, total ou parcialmente, por meio de publicação duplicada, publicação redundante ou reciclagem de texto. Logo, a reposta para a pergunta é não.

0 autoplágio não é legitimado pelo direito moral do autor. Entretanto, isso não quer dizer que seja proibido, tendo em vista que não há nenhuma previsão normativa que vede a referida prática no ordenamento jurídico nacional.

Por outro lado, é preciso ter em mente que "o elemento essencial do direito de autor é o poder absoluto que tem o criador sobre sua obra" (ASCENÇÃO, 1997, p. 542). Nesse sentido, o autor pode fazer o que quiser com a sua criação, desde que não infrinja princípios jurídicos e direitos de terceiros, situações estas que podem ocorrer com o autoplágio, conforme é abordado nos próximos tópicos.

\section{AUTOPLÁGIO E BOA-FÉ}

A boa-fé, segundo Cicero, é tudo que importe lealdade, correção e conduta honesta (CíCERO apud LÔBO, 2011, p. 173). Comte-Spoville (1999, p. 152) a define como “[...] um fato, que é psicológico, e uma virtude, que é moral. Como fato, é a conformidade dos atos e das palavras com a vida interior, ou desta consigo mesma. Como virtude, é o amor ou o respeito à verdade, e a única fé que vale [...]”.

A boa-fé apesar de ser norma infraconstitucional, incide sobre todas as relações jurídicas da sociedade (PEREIRA, 2011, p. 18). A doutrina a divide em dois tipos: boa-fé subjetiva e boa-fé objetiva. A primeira se trata de "um estado psicológico em que a pessoa possui a crença de ser titular de um direito que em verdade só existe na aparência” (CHAVES; ROSENVALT, 2015, p. 141). A segunda se refere, entre outros conceitos, no dever de agir com lealdade e fidelidade (CARNEIRO, 2017, p. 309)e é característica das relações obrigacionais (PEREIRA, 2011, p. 18).

0 autoplágio é um atentado à boa-fé objetiva. 0 público-alvo dos trabalhos acadêmicos, isto é, os leitores e editores, possuem a expectativa de ineditismo sobre a obra. Quando o autor pratica o autoplágio, engana o seu público-alvo, e, com isso, torna-se desleal. Por exemplo: um pesquisador de um tema específico e pouco explorado, pode encontrar obras de um mesmo autor sobre a temática pesquisada, e, com isso, acreditar que encontrou fundamentação para sua pesquisa. En- 
tretanto, ao verificar o conteúdo dos trabalhos, identifica publicação duplicada ou redundante ou reciclagem de texto. Logo, buscando a integridade científica, não poderá utilizar em sua pesquisa as obras como se fossem diferentes.

Outro exemplo que ilustra a deslealdade do autoplágio é o fato dos periódicos, em sua maioria, solicitar declaração de que o manuscrito submetido é uma contribuição original e inédita. Ao realizar o autoplágio, o autor burla as regras da revista, enganando os editores.

Apesar de ser uma violação à boa-fé, o autoplágio não pode ser considerado um ato ilícito apenas em razão desse motivo. Nesse caso, trata-se somente de uma infração ética que deve ser desestimulada. Mas se for contra uma editora, um periódico ou uma instituição de ensino ou pesquisa, entre outros, pode-se configurar uma inadimplência obrigacional e incidir as sanções previsto no termo estabelecido entre o autor e a organização. Portanto, nessa hipótese, pode-se considerá-lo como um ato ilícito (ZANINI, 2017, on-line).

\section{AUTOPLÁGIOE RELAÇ̃̃ES OBRIGACIONAIS}

Uma relação obrigacional é aquela em que uma parte fica obrigada a cumprir uma prestação em proveito de outra. Havendo o descumprimento, há um ilícito (GANGLIANO; PAMPLONA, 2017, p. 74). Existem pelo menos duas hipóteses em que o Autor pode ter uma relação obrigacional com outrem em relação à sua pesquisa: com a editora e com a empresa ou instituição em que labora.

O Autor quando submete um trabalho acadêmico a um periódico ou editora, geralmente celebra com estes um contrato de cessão de direitos autorais. Nesse contrato, em regra, há uma limitação no uso, no todo ou em parte, por outra publicação, e o autor transfere os seus direitos patrimoniais para o editor (CARVALHO; BRITO, 2018, p. 43; DINIZ, 2018, p. 203). 0 texto passa a ser propriedade do periódico ou da editora, tendo o autor os direitos morais sobre a obra.

Assim, quando o autor realiza autoplágio, passa a utilizar um texto que embora tenha elaborado, não the pertence mais. Ou seja, ele não pode mais dispor do texto, pois este pertence ao editor. O seu direito sobre o texto é exigir que ele permaneça integral, alterá-lo ou exigir que o seu nome esteja sempre vinculado à obra.

Nessa situação, quando o autoplágio viola o direito do editor sobre o texto publicado, pode-se falar em ato ilícito, pois é como se o autor cometesse um furto contra o editor.

Algumas pesquisas são solicitadas pelo empregador do Autor, e, em alguns casos, está previsto no contrato de trabalho que o resultado da pesquisa pertence ao empregador, resguardado ao Autor os direitos morais. Em alguns casos, permite-se que o Autor publique o texto em uma revista. Quando este comete autoplágio, pode estar violando o contrato de trabalho, pois está dispondo de obra que não lhe pertence e cujo uso precisa de autorização. Nesse contexto, também haverá um ilícito.

Além disso, a Consolidação das Leis do Trabalho (CLT) - Decreto-Lei $n^{0} 5.452$, de $1^{0}$ de maio de 1943 - inclui como possibilidade de dispensa por justa causa a hipótese de o empregado praticar mau procedimento ou ato lesivo à honra e boa fama do empregador ou terceiros (BRASIL, 1943, art. 482). 0 
autoplágio pode satisfazer essa hipótese, diante da possibilidade de repercutir negativamente sobre a reputação do empregador (CAMARGOS, 2015, p. 51).

Portanto, sempre que o autoplágio se configurar uma violação a uma relação obrigacional, independente que seja com o editor ou empregador, será considerado um ilícito (GIMENEZ; GIMENEZ; BORTULUCCE, 2014, p. 2; ZANINI, 2017, on-line).

\section{AUTOPLÁGIO E COSTUME JURÍDICO}

No Brasil a legislação é a principal fonte do ordenamento jurídico, mas isso não afasta a possibilidade de existir normas costumeiras, cujo processo de criação não é institucionalizado, mas espontâneo, dentro da própria sociedade (NADER, 2005, p. 57; MOTTA; FORTALEZA, 2018, p. 19).

O costume jurídico "é a norma jurídica que resulta de uma prática geral constante e prolongada, observada com a convicção de que é juridicamente obrigatória” (SIQUEIRA JUNIOR, 2019, p. 98). Ele é utilizado como mecanismo de interpretação da lei, mas também como fonte subsidiária, isto é, pode ser empregado para suprir uma lacuna normativa (DINIZ, 2002, p. 185).

Na sociedade, existem vários costumes, mas não são todos que podem ser considerados possuintes de normatividade jurídica. A doutrina tem estabelecido dois requisitos para poder identificar quando um costume tem força normativa, são eles: uso uniforme, constante, público e geral; e, a convicção de obrigatoriedade (DINIZ, 2002, p. 185; FERRAZ JR., 2015, p. 199).

No direito educacional, existem vários costumes que possuem força normativa, por exemplo, pedido de revisão de prova e realização de segunda-chamada. Alguns, inclusive, foram positivados, como é o caso do pedido de documentos escolares (JOAQUIM, 2005, on-line).

Acredita-se que a repressão ao autoplágio se constitui um costume jurídico, por satisfazer os requisitos do uso constante e da convicção de obrigatoriedade.

Há no âmbito acadêmico uma prática comum de reprimir o autoplágio. Trabalhos não são aprovados por instituições de ensino ou são excluídos de periódicos quando verificado a referida infração ética. Existe um constante desestímulo por parte de orientadores, instituição de pesquisa, periódicos, inclusive do Ministério da Educação, para que pesquisadores não pratiquem autoplágio. Atualmente ele é tema de editoriais, artigos de opinião, artigos científicos, entre outros (FURLANETTO; RAUEN; SIEBERT, 2018, p. 14; ASSIS, 2019, p. 96)

Nos guias para integridade de pesquisa acadêmica das instituições de pesquisa e de ensino e de periódicos, assim como, em regimento interno de faculdades, têm surgido cláusulas que sancionam a prática do autoplágio. É o caso da Universidade Federal do Paraná (BRASIL, 2018, p. 7-8), da Universidade Estadual de Campinas (SÃO PAULO, 2020, p. 07), da Universidade Federal do Rio Grande do Sul (BRASIL, 2020, p. 21), da Academia Brasileira de Ciência (2013, p. 11), da Fundação Oswaldo Cruz (BRASIL, 2019, p. 19), entre outros.

Ressalta-se que a Comissão de Integridade de Pesquisa do Conselho Nacional de Desenvolvimento Científico e Tecnológico (CNPq), classificou o autoplágio como uma má conduta na pesquisa cientifica, 
que causa danos ao conhecimento acadêmico e que serve de meio de burlar regras para obter autopromoção (BRASIL, 2012, p. 4). Com isso, o relatório estabelece as seguintes diretrizes para os autores:

\section{$[\ldots]$}

5:Quando se submete um manuscrito para publicação contendo informações, conclusões ou dados que já foram disseminados de forma significativa (p.ex. apresentado em conferência, divulgado na internet), o autor deve indicar claramente aos editores e leitores a existência da divulgação prévia da informação.

6: se os resultados de um estudo único complexo podem ser apresentados como um todo coesivo, não é considerado ético que eles sejam fragmentados em manuscritos individuais. 7: Para evitar qualquer caracterização de autoplágio, o uso de textos e trabalhos anteriores do próprio autor deve ser assinalado, com as devidas referências e citações. []. (BRASIL, 2012, p. 5).

Esses fatos demonstram que a repressão ao autoplágio é de uso constante e possui uma convicção de obrigatoriedade, portanto, trata-se de um costume jurídico.

Isso se confirma por meio de um lígio que o Poder Judiciário brasileiro teve a oportunidade de apreciar, cuja decisão é um precedente sobre a temática, isto é, uma diretriz para julgamento de outros casos semelhantes no país².

Trata-se do litígio entre a Universidade Católica de Pelotas e uma aluna do curso de direito. Esta havia reaproveitado integralmente pesquisa realizada em coautoria com demais colegas, como trabalho de conclusão de curso, modificando, apenas, o título do trabalho. A banca reprovou a aluna por plágio e autoplágio (RIO GRANDE DO SUL, 2016).

Inconformada, a aluna moveu uma ação judicial contra a instituição de ensino, solicitando reparação por dano moral pela suposta humilhação que havia sido submetida. O Poder Judiciário do Rio Grande do Sul entendeu que o dano moral não restou configurado. Um dos argumentos alegados pela aluna foi de que o seu trabalho de conclusão de curso não poderia ter sido considerado como plágio, em virtude de ela ter sido a autora do trabalho, bem como, porque no regulamento do trabalho de conclusão (TCC) de curso da universidade não havia previsão de reprovação por este motivo (RIO GRANDE DO SUL, 2016).

A juíza de primeira instância, ao analisar o caso, entendeu que na hipótese de os coautores terem concordado com a utilização da pesquisa pela aluna (o que não ficou demonstrado no processo), poderia não se configurar como plágio. Todavia, o fato dela ter utilizado uma obra sua, que não era nem original, nem inédita como TCC, seria prática de autoplágio. A referida juíza justificou que "o autoplágio não deixa de ser uma "burla' ao sistema de produção acadêmica e, por isso mesmo, sendo contrário à boa ética” (RIO GRANDE DO SUL, 2016), legitimando, com isso, a reprovação da aluna. Esta recorreu da decisão, mas ela foi confirmada, em segunda instância, pelo Tribunal de Justiça do Rio Grande do Sul (RIO GRANDE DO SUL, 2017).

Esse caso demonstra como a repressão ao autoplágio é um costume jurídico, uma vez que não havia norma institucional que sancionasse aluno que praticasse autoplágio, mas apesar disso, a banca avaliadora reprovou a aluna por esse motivo, posicionamento confirmado pelo Poder Judiciário.

2 Na pesquisa por jurisprudência no sistema JusBrasil, encontrou-se apenas esse julgado que trata diretamente sobre o tema. 


\section{CONSIDERAÇÕES FINAIS}

O autoplágio é uma infração ética no âmbito da pesquisa científica, consubstanciada como reaproveitar uma pesquisa, total ou parcialmente, como se fosse inédita e original, em outro local, buscando burlar o sistema de produção acadêmica e/ou alcançar a autopromoção.

Essa prática apesar de ser desestimulada e ter bastante repercussão dentro da academia, não se encontra proibida por meio da legislação. Nem mesmo pode ser considerada uma violação aos direitos autorais, mas também não é legitimada por este, como muitos pensam.

A prática do autoplágio é uma violação à boa-fé objetiva, tendo em vista que induz uma pessoa a acreditar que um trabalho ou parte dele é inédito, quando, na verdade, não é, frustrando a expectativa de ineditismo do leitor. Mas isso não é suficiente para classificá-lo como um ilícito, apenas como uma infração ética.

Todavia, se o autoplágio se configurar como uma violação ao princípio da boa-fé objetiva no contexto das relações obrigacionais, como é o caso da relação entre autor e editor, será um ilícito, pois trata-se de uma violação aos direitos do editor, em decorrência de um contrato de cessão de direitos autorais. Destaca-se que isso pode ocorrer também no âmbito trabalhista, em que o autoplágio pode ser considerado uma transgressão ao contrato de trabalho.

Para além das relações contratuais, no âmbito acadêmico existe a consciência coletiva que autoplágio se trata de um desvio ético que deve ser coibido, sendo usualmente reprimido, o que faz da repressão ao autoplágio um costume jurídico e do autoplágio um ilícito.

\section{REFERÊNCIAS}

ACADEMIA Brasileira de Ciência. Rigor e integridade na condução da pesquisa científica: guia de recomendações de práticas responsáveis, 2013. Disponível em: http://www.abc.org.br/IMG/pdf/doc4559.pdf. Acesso em: 17 dez. 2020.

AFONSO, Otávio. Direito autoral: conceitos essenciais. Barueri, SP: Manole, 2009.

ASCENSÃO, José de Oliveira. Direito autoral. Rio de Janeiro: Renovar, 1997.

ASSIS, Alan Jhones Barbosa de; HOLANDA, Cleonice Andrade; AMORIM, Rivadávio Fernandes Batista de. A new side of an old problem: self-plagiarism in scientific publications. Geriatrics, Gerontology and Aging, v. 13, n. 2, 2019. Disponível em: http://ggaging.com/details/533/en-US/nova-face-de-umvelho-problema--o-autoplagio-no-cenario-da-producao-cientifica. Acesso em: 22 jan. 2021.

BARRAGÁN-VERGEL, María Fernanda. Autoplagio y duplicación: un asunto en contra de la ética en la investigación científica. MedUNAB, p. 293-295, 2018. Disponível em: https://revistas.unab. 
edu.co/index.php/medunab/article/view/3248. Acesso em 17 de dez. 2021. DOI: https://doi. org/10.29375/01237047.3248. Acesso em: 22 jan. 2021.

BRASIL. Universidade Federal do Rio Grande do Sul. Guia para integridade em pesquisa científica, 2020. Disponível em: https://www.ufrgs.br/propesq1/propesq/wp-content/uploads/2020/06/guiapara-integridade-em-pesquisa-cientifica.pdf. Acesso em: 17 dez. 2021.

BRASIL. Ministério da Saúde. Fundação Oswaldo Cruz. Guia de Integridade em Pesquisa da Fiocruz, novembro de 2019. Disponível em: https://portal.fiocruz.br/sites/portal.fiocruz.br/files/ documentos/guia_de_integridade_em_pesquisa_da_fiocruz_-_final.pdf. Acesso em: 17 dez. 2021.

BRASIL. Universidade Federal do Paraná. Instrução Normativa nº 2 - CPDCT/PRPPG/UFPR, Curitiba, julho de 2018. Dispõe de recomendações de boas práticas, rigor e integridade na pesquisa científica. Disponível em: http://www.prppg.ufpr.br/site/wp-content/uploads/2019/02/in_02_ cpdct.pdf. Acesso em: 17 dez. 2021.

BRASIL. Ministério da Ciência, Tecnologia, Inovações e Comunicações. Conselho Nacional de Desenvolvimento Científico e Tecnológico. Relatório da Comissão de Integridade de Pesquisa do CNPq de 20 de abril de 2012. Disponível em:

https://www.gov.br/cnpq/pt-br/composicao/comissao-de-integridade/relatorio-comissao-integridade-do-cnpq.pdf/view . Acesso em: 17 dez. 2021.

BRASIL. Lei n 9.610, de 19 de fevereiro de 1998. Altera, atualiza e consolida a legislação sobre direitos autorais e dá outras providências. Disponível em: http://www.planalto.gov.br/ccivil_03/leis/ 19610.htm. Acesso em: 17 dez. 2021.

CAMARGOS, Luciano Borges. 0 plágio da obra escrita no ambiente acadêmico e suas consequências. 2018. 74 f. Dissertação (Mestrado Profissional em Inovação Tecnológica) - Universidade Federal do Triângulo Mineiro, Uberaba, MG, 2018. Disponível em: http://200.131.62.27/handle/tede/644. Acesso em: 22 jan. 2021

CARNEIRO, Wálber Araújo. Boa-fé intersubjetiva: das impossibilidades do espírito objetivo à ressignificação heterorreflexiva. In: PAMPLONA FILHO, Rodolfo; BRAGA, Paula Sarno; LARGO JÚNIOR, Antônio (coord.). Ética e boa-fé no direito: estudos em homenagem ao professor Adroaldo Leão e sua obra "o litigante de má-fé". Salvador: Juspodivm, 2017.

CARVALHO, Alexander Perazo Nunes; BRITO, Anya Lima Penha. Autoplágio: uma violação ao direito à integridade intelectual? Rev. de Pesquisa e Educação Jurídica, Porto Alegre, v. 4, n. 2, p. 35- 50, jul./dez. 2018. Disponível em: https://indexlaw.org/index.php/rpej/article/view/4877.

Acesso em: 22 jan. 2021. 
COMTE-SPONVILLE, André. Pequeno tratado das grandes virtudes. São Paulo: Martins Fontes: 1999.

COSTA NETTO, José Carlos. Direito autoral no Brasil. São Paulo: Saraiva Educação, 2019.

CULEBRAS, J. M.; GARCÍA DE LORENZO, A.; SANZ-VALERO, J. Reflexiones en torno a los conflictos éticos de la literatura científica: la publicación repetitiva, duplicada o redundante. Nutrición Hospitalaria, v. 24, n. 4, p. 375-377, 2009. Disponível em: https://scielo.isciii.es/pdf/nh/v24n4/ editorial.pdf. Acesso em: 22 jan. 2021.

DAMASIO, Edilson. Práticas de má conduta na comunicação científica e o fluxo editorial: um estudo com editores de revistas científicas SciELO. Rio de Janeiro, 2017.196 f. Tese (Doutorado em Ciência da Informação) - Universidade Federal do Rio de Janeiro, Escola de Comunicação, Instituto Brasileiro de Informação em Ciência e Tecnologia, Programa de Pós-Graduação em Ciência da Informação, Rio de Janeiro, 2017. Disponível em: https://ridi.ibict.br/handle/123456789/946. Acesso em: 22 jan. 2021.

DINIZ, Débora; TERRA, Ana. Plágio: palavras escondidas. Brasília: Letras Livres; Rio de Janeiro: Fiocruz, 2014.

DINIZ, Eduardo H. O Gato que copia: similaridades e produção acadêmica na Era Digital. Rev. adm. empres., São Paulo, v. 58, n. 2, p. 201-205, mar. 2018. . DOI: https://doi.org/10.1590/s0034759020180208. Disponível em: http://www.scielo.br/scielo.php?script=sci_arttext\&pid=S0034$75902018000200201 \& l n g=e n \& n r m=i s o$. Acesso em: 22 jan. 2021.

FURLANETTO, Maria Marta; RAUEN Fábio José; SIEBERT, Silvânia (ed.). Plágio e autoplágio: desencontros autorais. Linguagem em (Dis)curso - LemD, Tubarão, SC, v. 18, n. 1, p. 11-19, jan./ abr. 2018. Disponível em: https://www.scielo.br/j/ld/a/B4bbw7ZyVjh8XnGHQJrKgzG/?lang=pt. Acesso em 22 de jan. 2021.

GAGLIANO, Pablo Stolze; PAMPLONA FILHO, Rodolfo. Novo curso de direito civil, volume 2: obrigações. São Paulo: Saraiva, 2017.

GIMENEZ, Ana Maria Nunes; GIMENEZ, Claudemir; BORTULUCCE, Vanessa Beatriz. O direito do autor e o autoplágio: entre o lícito, ilícito e o antiético. Reunião Anual da Sociedade Brasileira para o progresso da ciência, 66, 2014. Anais [...], 2014. DOI: https://doi.org/10.13140/2.1.4053.0249 .Disponível em: https://www.researchgate.net/publication/271213116_O_DIREITO_DO_ AUTOR_E_O_AUTOPLAGIO_ENTRE_O_LICITO_ILICITO_E_O_ANTIETICO. Acesso em: 22 jan. 2021.

GONÇALVES, Carlos Roberto. Direito civil brasileiro, volume 3: contratos e atos unilaterais. São Paulo: Saraiva, 2012. 
JOAQUIM, Nelson. Direito educacional: o quê? para quê? e para quem? Revista Jus Navigandi, Teresina, ano 10, n. 693, 29 maio 2005. ISSN 1518-4862. Disponível em: https://jus.com.br/ artigos/6794. Acesso em: 22 jan. 2021.

LÔBO, Paulo. Direito civil: contratos. São Paulo: Saraiva, 2011

MAIA, Helena Fraga. "Salami science” ou “salami slicing”: uma reflexão sobre a produção científica.

Revista Pesquisa em Fisioterapia, v. 7, n. 1, p. 3-5, 2017. Disponível em: https://www5.bahiana. edu.br/index.php/fisioterapia/article/view/1235/0. Acesso em: 22 jan. 2021

NADER, Paulo. Introdução ao estudo do direito. Rio de Janeiro: Forense, 2005.

PAESANI, Liliama Minardi. Manual de propriedade intelectual. São Paulo: Atlas, 2015.

PEREIRA, Caio Mario da Silva. Instituições do direito civil. Volume III. Rio de Janeiro, Editora Forense, 2011.

RIO GRANDE DO SUL. Poder Judiciário. Apelação Cível nº 70073816738 (Nº CNJ: 014578845.2017.8.21.7000. Responsabilidade Civil. Relator: Jorge Alberto Schreiner Pestana. Porto Alegre, 30 de novembro de 2017.

RIO GRANDE DO SUL. Poder Judiciário. Responsabilidade Civil. Comarca de Pelotas. $5^{a}$ Vara Cível. Processo de n⿳0 022/1.15.0006467-8 (CNJ:.0013392-57.2015.8.21.0022). Juíza prolatora: Rita de Cássia Müller. Pelotas-RS, 2 de dezembro de 2016.

REJOWSKI, Mirian; RODRIGUES, Vanuza Bastos. Autoplágio e pesquisa científica: moral e ética na pós-graduação em Turismo e Hospitalidade. Revista Rosa dos Ventos Turismo e Hospitalidade, v. 10, n. 4, p. 814-828, 2018. DOI: http://dx.doi.org/10.18226/21789061.v10i4p814. Disponível em: http:// www.ucs.br/etc/revistas/index.php/rosadosventos/article/view/5852. Acesso em: 22 jan. 2021.

ROIG, Miguel. Avoiding plagiarism, self-plagiarism, and other questionable writing practices: a guide to ethical writing. 2015. Second revision. Disponivel em: https://bsc.ua.edu/wp-content/uploads/2017/07/plagiarism-1.pdf. Acesso em: 22 jan. 2020.

SÃO PAULO. Universidade Estadual de Campinas. Deliberação CONSU-A-049/2020, de 6 de outubro de 2020. Institui a Política Institucional de Boas Práticas e Integridade em Pesquisa da Universidade Estadual de Campinas e a cria a Comissão de Integridade em Pesquisa (CIP). Disponível em: https://www.pg.unicamp.br/mostra_norma.php?id_norma=23868.

Acesso em: 17 dez. 2021. 
SATUR, Roberto Vilmar; DIAS, Guilherme Ataíde; SILVA, Armando Malheiro da. Direito autoral, plágio e coautoria: questões acadêmicas e éticas. Brazilian Journal of Information Science, v. 14 n. 1, p. 57-87, jan./mar. 2020. DOI: 10.36311/1981-1640.2020.v14n1.04.p57. Disponível em: https:// revistas.marilia.unesp.br/index.php/bjis/article/view/8889. Acesso em: 22 jan. 2021.

SAUSSURE, Ferdinand. Curso de linguística geral. São Paulo: Cultrix, 2006.

SOUZA, Allan Rocha. Os direitos morais do autor. Civilistica.com: revista eletrônica de direito civil, v. 2, n. 1, p. 1-23, 2013. Disponível em: https://civilistica.emnuvens.com.br/redc/article/view/73.

Acesso em: 22 jan. 2021.

WACHOWICZ, Marcos. Direito autoral. GEDAI, v. 13, p. 1-12, 2014. Disponível em: http://www.gedai. com.br/wp-content/uploads/2014/07/artigo_marcoswachowicz_direitoautoral_6-1.pdf.

Acesso em: 22 jan. 2021.

ZANINI, Leonardo Estevam de Assis. Notas sobre o plágio e a contrafação. Revista de Doutrina da $4^{\text {a }}$ Região, Porto Alegre, n. 81, dez. 2017. Disponível em: http://revistadoutrina.trf4.jus. br/artigos/edicao081/Leonardo_Estevam_Zanini.html. Acesso em: 22 jan. 202. 


\section{(2) (1) (-)}

Este artigo é licenciado na modalidade acesso abertosob a Atribuição-Compartilhalgual CC BY-SA

1 Mestre em Propriedade Intelectual e Transferência de Tecnologia para Inovação pelo IFBA (2020); Especialista em Gestão da Inovação e Desenvolvimento Regional pela UFRB (2017); Bacharel em Direito pela Universidade do Estado da Bahia (2014); Advogado; Professor de Direito; Membro da Comissão de Propriedade Intelectual da OAB/BA. 